\title{
Supervivencia del injerto y del receptor en el trasplante renal en el hospital Guillermo Gran Benavente (Concepción, Chile)
}

\author{
Magali Rodríguez Vidal' ${ }^{1}$, Mariela Parra Morales ${ }^{1}$, Susana Rocha Ortiz², Manuel Castro Salas ${ }^{1}$, Claudia \\ Villalobos Sepúlveda² \\ ${ }^{1}$ Universidad de Concepción, ${ }^{2}$ Unidad de Trasplante, Hospital Regional, Concepción. Chile
}

\section{Resumen}

Al ser el trasplante renal la mejor opción terapéutica para el tratamiento de la Insuficiencia Renal Terminal, en la ciudad de Concepción (Chile), se inició el programa de Trasplante Renal (TX) en el año 1994. El objetivo de este trabajo es caracterizar la supervivencia del injerto renal de los TX realizados un hospital, de dicha ciudad mediante un estudio descriptivo, transversal, correlacional y comparativo de los resultados obtenidos en dos periodos, $\mathrm{A}$ : de 1994 a 2003 y, B: de 2004 a 2012.

El análisis estadístico se realizó con el software SPSSv20.0. La funcion de supervivencia con la prueba no-paramétrica de Kaplan-Meier; y para comparaciones de variables se utilizó el test log-rank.

De los resultados obtenidos cabe destacar que la supervivencia del paciente trasplantado en el período A fue mejor el primer al año $(96 \%)$, pero fue menor a los $3(90 \%)$, $5(86 \%)$ y 10 años $(72 \%)$ respecto al período $B$ en que los valores fueron al año 95\%, a los 3 el $90 \%$ a los 5 y 10 años el $87 \%$ y a los 10 años. La supervivencia del injerto tambien fue mayor en el periodo $A$ que en el $B, y$ mejor cuando hubo un tiempo de isquemia inferior a 24 horas y sin diferencias en relación al sexo del donante y del receptor y al tipo de tratamiento inmunosupreso. Las infeciones fueron la primera causa de muerte del paciente y las complicaciones quirúrgicas la principal causa de la pérdida del injerto.

\section{PALABRAS CLAVE}

- TRASPLANTE RENAL

- SUPERVIVENCIA

- COMPLICACIONES

\section{Correspondencia:}

Magali Rodríguez Vidal

Victor Lamas 210 casilla160-C. Concepción. Chile

E-mail: magrodri@udec.cl
Survival of the graft and the host in renal transplant in the Guillermo Gran Benavente Hospital (Concepción, Chile)

\section{Abstract}

As the renal transplant is the best therapeutic option for the treatment of End-Stage Renal Disease, in the city of Concepción (Chile), a Renal Transplant Program (TX) was started in 1994. The aim was to characterize the kidney graft survival of TX performed in our hospital, through a descriptive, transversal, correlational and comparative study of the results obtained in two periods, A: from 1994 to 2003 and, B: from 2004-2012.

Statistical analysis was performed using the SPSSv20.0 software. The function of survival was calculated using the nonparametric Kaplan-Meier test; and to compare the variables we used the log-rank test.

From the results, we emphasize that the survival of patients transplanted in the period $A$ was better in the first year $(96 \%)$, but was lower at $3(90 \%), 5(86 \%)$ and 10 years ( $72 \%$ ) compared to the period $B$ in which the first year was $95 \%$, at 3 of $90 \%$ at 5 and 10 years of $87 \%$. Graft survival was also higher in the period A than in $B$, and better when the time of ischemia was less than 24 hours and no differences in relation to sex of the donor and recipient and type of immunosuppressive treatment. Infections were the first cause of death and surgical complications the main cause of graft loss.

\section{KEYWORDS}

- RENAL TRANSPLANTATION

- SURVIVAL

- COMPLICATIONS 


\section{Introducción}

La Enfermedad Renal Crónica (ERC) es un problema de salud pública que afecta a la población a nivel mundial, con una incidencia y prevalencia que va en ascenso que ha experimentado un crecimiento de 30 veces en 30 años, En el mundo existe un aumento progresivo del número de pacientes con ERCT, que requieren tratamiento de sustitucion renal debido a una mayor incidencia de enfermedades cronicas, como diabetes mellitus, e hipertensión ${ }^{1}$.

Actualmente, el mejor tratamiento de la ERCT es el Trasplante $(T x)^{2,3}$, que se proyecta como la unica solución integral, que permite una, óptima rehabilitación y mejor calidad de vida asociada a la reducción de la morbimortalidad y costo económico siendo la mejor alternativa de tratamiento ${ }^{4}$.

El Tx y donación de órganos ha sido definido como el proceso mediante el cual, se logra que los organos y tejidos de alguien que ha fallecido sean implantados en un receptor determinado, asumiendo el profesional de enfermería la responsabilidad de organizar, coordinar y asistir todas las actividades derivadas de las diferentes etapas del proceso, desde la localización del donante, la implantación del órgano, tratamiento y seguimiento posterior ${ }^{9}$. A pesar de ser la mejor opción, es un procedimiento, que no está exento de complicaciones, algunas de tal magnitud que pueden acabar con la vida del usuario o llevar a la perdida del injerto ${ }^{2}$.

El Tx es una técnica terapéutica que para su realización, depende de la disponibilidad de organos identificándose tres tipos de donantes: donante vivo, donante cadaver en muerte encefálica y donación de cadáver en asistolía 0 a corazón parado ${ }^{5}$, que deben ser evaluados tanto en la compatibilidad con el receptor (en relación a grupo sanguíneo y $\mathrm{Rh}$, y pruebas de histocompatibilidad) como en el estado de salud de él mismo, siendo exhaustivos en la función renal y tratando de predecir la posibilidad de fallo renal posterior junto con las características que permitan que el trasplante sea óptimo ${ }^{6}$.

El donante cadáver por muerte cerebral y el donante cadáver a corazón parado es una persona que ha presentado interrupción irreversible de todas las funciones cerebrales o encefálicas, pero que conserva las funciones circulatorias y respiratorias ${ }^{7}$.

La supervivencia del paciente y del órgano trasplantado, esta determinada por una serie de variables entre las cuales las más estudiadas son: tiempo de isquemia, edad del donante y receptor, estudio de histocompatibilidad, sexo, tratamiento inmunosupresor, peso, talla, indice de masa corporal entre otras.

Por la repercusión que tiene en el desarrollo posterior de la ERCT post Tx es necesario conocer las condiciones de la parada cardiaca, maniobras de reanimación cardiopulmonar, procedimiento de obtención de órganos y el tiempo que ha durado cada una de las fases. Entre estos controles tiene especial importancia el tiempo de isquemia, que es el tiempo en que se produce la parada cardiaca hasta que se comienza a enfriar el órgano (isquemia caliente), y el tiempo que transcurre desde el enfriamiento del órgano hasta que es implantado (isquemia fría). El tiempo máximo de isquemia fría para el riñón son $30 \mathrm{hrs}^{8}$

En Chile a diciembre del 2011 existian 1.642 pacientes en lista de espera para todo tipo de Tx de estos 1.356 correspondian a Tx renal, aunque sólo 195 pacientes lo recibieron.

El objetivo de esta investigación fué conocer y relacionar los factores que están involucrados en la supervivencia del injerto renal,como tambien las causas más frecuentes de muerte y de pérdida del injerto del paciente trasplantado renal, con el fin de descubrir las desviaciones que se han producido en la experiencia local, de modo que en base a esta información se pueda optimizar el trabajo del equipo de salud.

\section{Metodología}

La investigación realizada correspondió a un estudio descriptivo, transversal, correlacional y comparativo. La unidad de análisis correspondió a cada uno de los pacientes trasplantados entre enero 1994 a julio 2013, considerandose dos periodos: A (de 1994 a 2003) y B (de 2004 a 2013). La población estuvo constituida por 234 pacientes atendidos en el Hospital Guillermo Grant Benavente. Los criterios de inclusión fueron: pacientes trasplantados entre enero 1994 a julio 2013, que perdieran el injerto en cualquier etapa post trasplante y pacientes que fallecieran con injerto funcionante. Se excluyó a los pacientes que pertenecian a un sistema sanitario privado, por no continuar su control en el hospital.

El instrumento recolector de datos, se estructuró de acuerdo a las siguientes variables: supervivencia del injerto y receptor, tipo de donante, características del donante y receptor (edad,sexo,estado,civil), horas de isquemia fría, tratamiento inmunosupresor, causas de muerte 
y causas de pérdida del injerto. Los datos se obtuvieron de la revisión de las historias clinicas de los pacientes.

El proyecto fué sometido a revisión del Comité de Ética de la Facultad de Medicina de la Universidad de Concepción. La información fué tratada con total privacidad, adoptando todas las medidas necesarias para que los pacientes no fueran identificados en su individualidad.

El control de calidad de la información se llevó a cabo realizando una exaustiva revisión de los datos ingresados. El análisis estadístico se realizó con el software SPSS v20.0. Las funcion de supervivencia fue obtenida utilizando la prueba no-paramétrica de KaplanMeier; y para comparar la supervivencia del injerto, con otras variables el test log-rank.

\section{Resultados}

Entre los dos periodos estudiados se llevaron a cabo 234 trasplante, 98 en el periodo A y 126 en el periodo $B$. La edad media del receptor en el período $A$ fue de 35 años en un rango de 11-64 años y en el período $B$ de 40 años (rango 14 - 63 años).

La supervivencia del paciente trasplantado en el período A (1994- 2003) fue mejor al año (96\%), pero disminuyo paulatinamente a los $3(90 \%), 5(86 \%)$ y 10 años (72\%). En el período B (2004-2012) la supervivencia al año fue del $95 \%$, a los 3 años del $90 \%$, a los 5 años del, $87 \%$ y a los 10 años se mantuvo en el $80 \%$ (Figura 1 ).
La supervivencia del injerto renal en el período $\mathrm{A}$ fue al año del $87 \%$ a los 3 del $82 \%$, y a los 5 del $79 \%$, decreciendo a los 10 años hasta el 59\%,. En el períod B la supervivencia del injerto fue inferior, observándose los cinco primeros años de trasplante, una disminución de la supervivencia del injerto en relación al período anterior pues al año fue de $83 \%$, a los 3 años del $77 \%$ a los 5 del $68 \%$ y a los 10 años del 64\% (Figura 2).

Respecto a la edad del donante categorizada según normas del Ministerio de Salud Chileno de 20069, se observó que en los grupos etáreos menores de 50 años porcentualmente hay una mejor supervivencia al año $(86 \%)$, a los $3(81 \%)$, a los $5(76 \%)$, y a los 10 años (71\%). En el período B se pudo observar que en los mayores de 51 años, se produce una caída abrupta de la supervivencia del injerto al año (78\%) a los 3años (63\%), a los 5 años (40\%) y a los 10 años (40\%).

En relación al tipo de donante en el período $\mathrm{A}$ el $\mathrm{Tx}$ procedente de donante vivo tuvo una supervivencia de $100 \%$, al año, cinco y diez años con diferencia significativa respecto del donante cadáver y en el segundo período esta fue $100 \%$ al año y a los 5 años y $87 \%$ a los diez años. (Figura 3).

Respecto al sexo del donante, en el período $\mathrm{A}$ hubo diferencia significativa a favor de una mayor supervivencia $(p=0.048)$ cuando el donante era de sexo femenino, mientras que en el segundo período no se encontraron diferencias.

En cuanto a la edad del receptor en el período $A$ no influyó en la supervivencia del injerto, mientras que en el

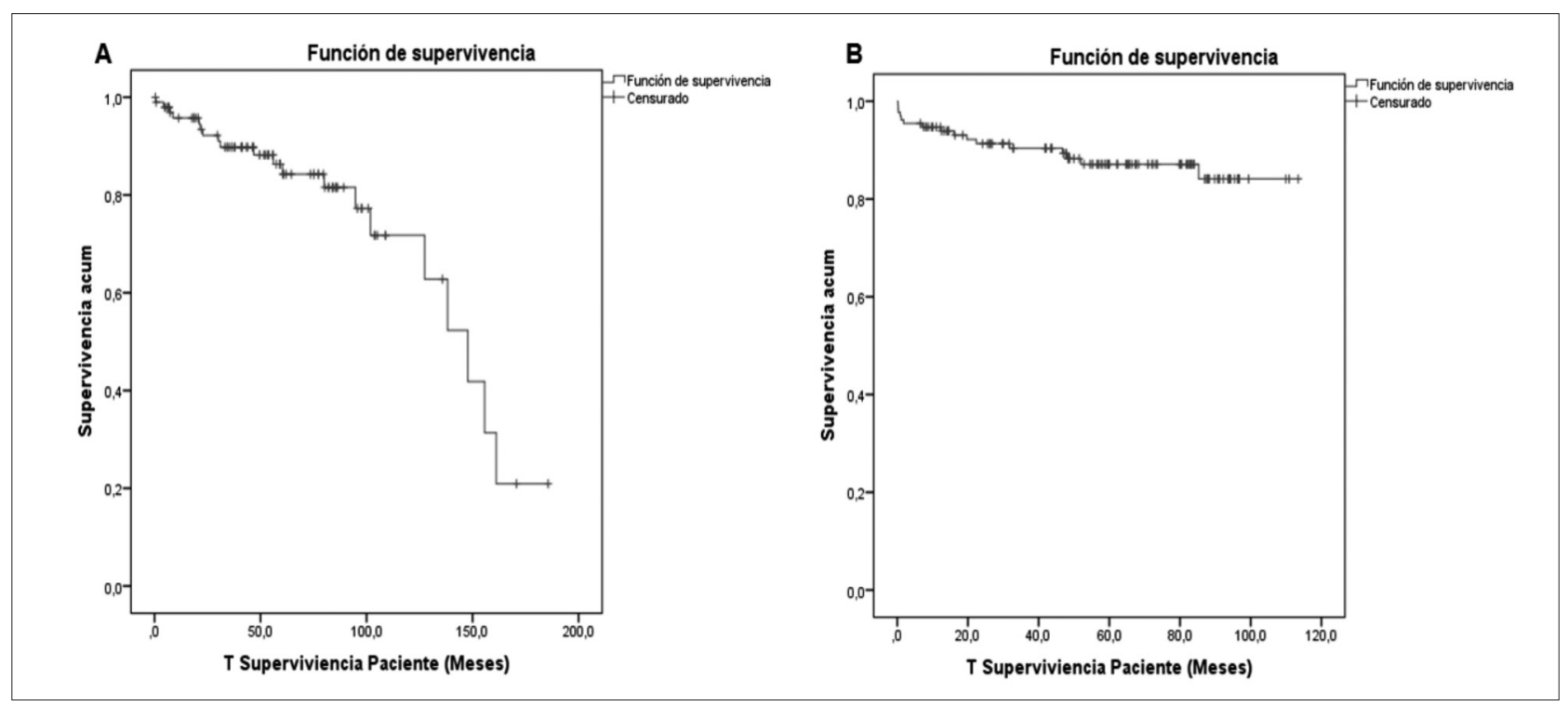

Figura 1. A. Curva de supervivencia de los pacientes trasplantados entre los años 1994-2003.

B. Curva de supervivencia de los pacientes trasplantados entre los años 2003-2012. 


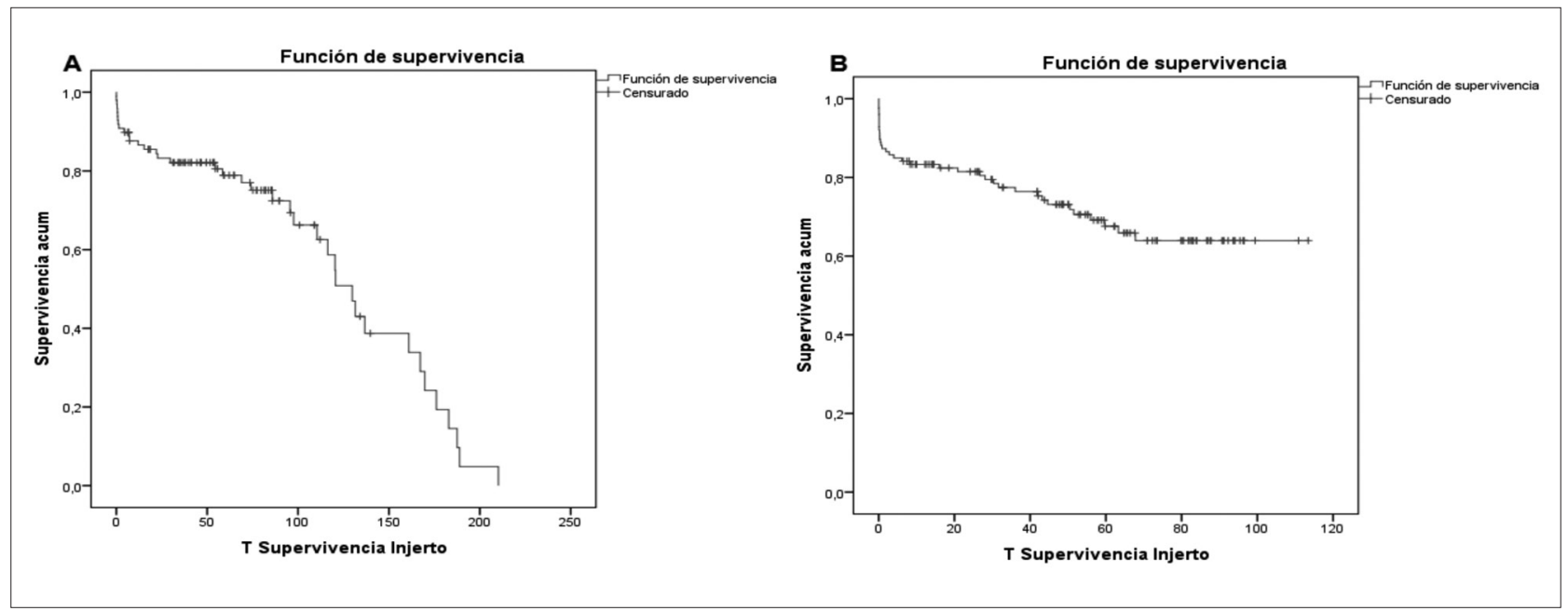

Figura 2. A. Curva de supervivencia del injerto renal de los pacientes trasplantados entre los años 1994-2003.

B. Curva de supervivencia de los pacientes trasplantados entre los años 2003-2012.

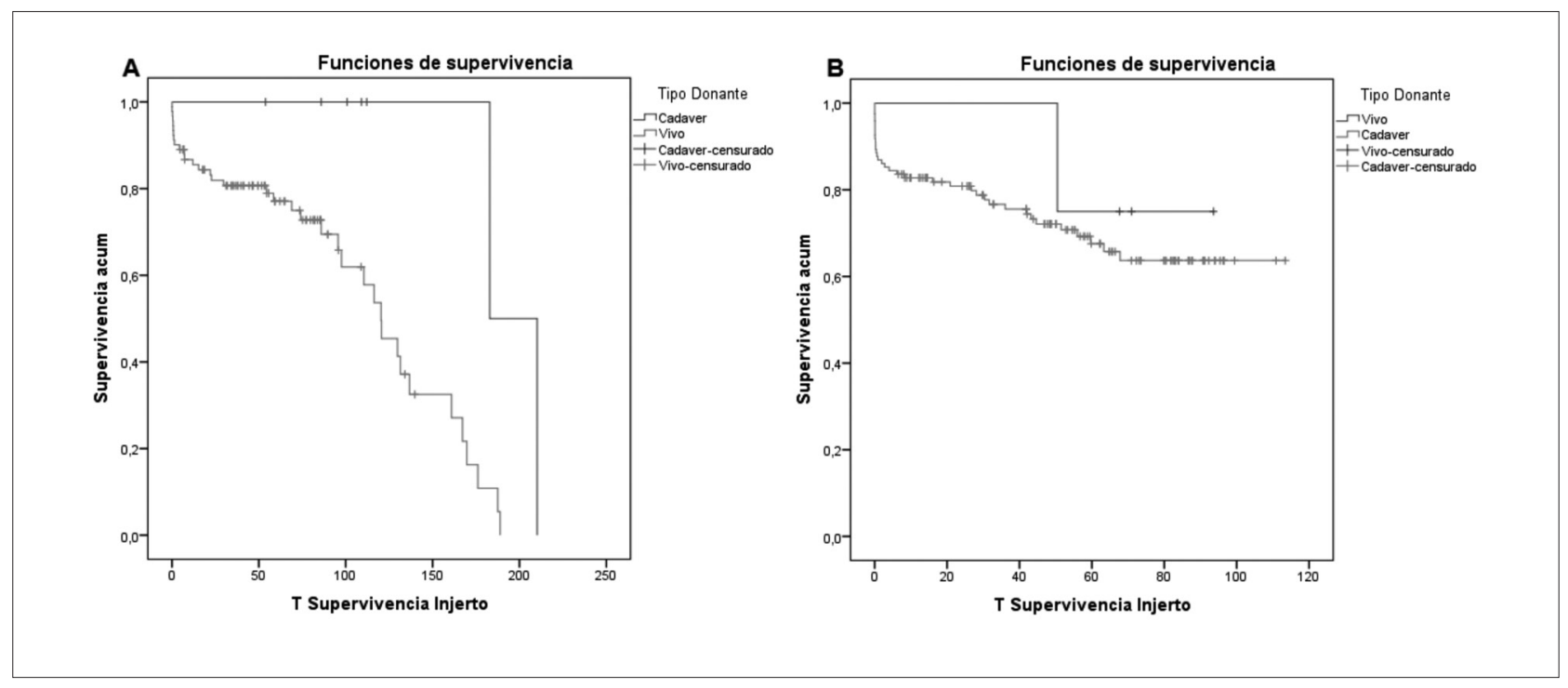

Figura 3. (A) Curvas de supervivencia del injerto renal de acuerdo al tipo de donante en el periodo 1994-2003. $n=99$; (B) Curvas de supervivencia del injerto renal de acuerdo al tipo de donante en el periodo 2004-2012. $n=126$.

período B esta variable presento diferencias estadísticas significativa $(p=0.000)$ a favor de la supervivencia del injerto. En relación al sexo del receptor, se apreció que en ambos períodos hubo diferencias estadísticas; sin embargo al observar la figura 4 se aprecia que la supervivencia del injerto en individuos de sexo masculino fue superior al sexo femenino en el primer período pero prácticamente se entrelazan ambas curvas en el segundo período.

El tiempo de isquemia fría solo pudo calcularse para el período $B$ ya que los datos del primer período se perdieron por causas del terremoto acaecido en la ciudad en 2010. En este periodo se observa que a los 5 años, los tiempos de isquemia menor a 24 horas reportan mayor supervivencia, mientras que en tiempos de isquemia mayores a 24 horas la supervivencia baja a un $60 \%$.

Respecto al tipo de tratamiento inmunosupresor primario en el período A, en un $96 \%$ de los Tx se usó la combinación de azatropina, ciclosporina y prednisona, en el período $B$, las combinaciones mas utilizadas fueron: pauta $1=$ azatropina, ciclosporina y prednisona; pauta $2=$ micofenolato, tacrolimus y pauta $3=$ prednisona $y$ micofenolato, pauta 4: ciclosporina y prednisona; ninguna mostro difrencias en cuanto a la supervivencia del injerto. Las causas de muerte más frecuentes en el período A fueron cardiovasculares, infecciosas y cáncer; 


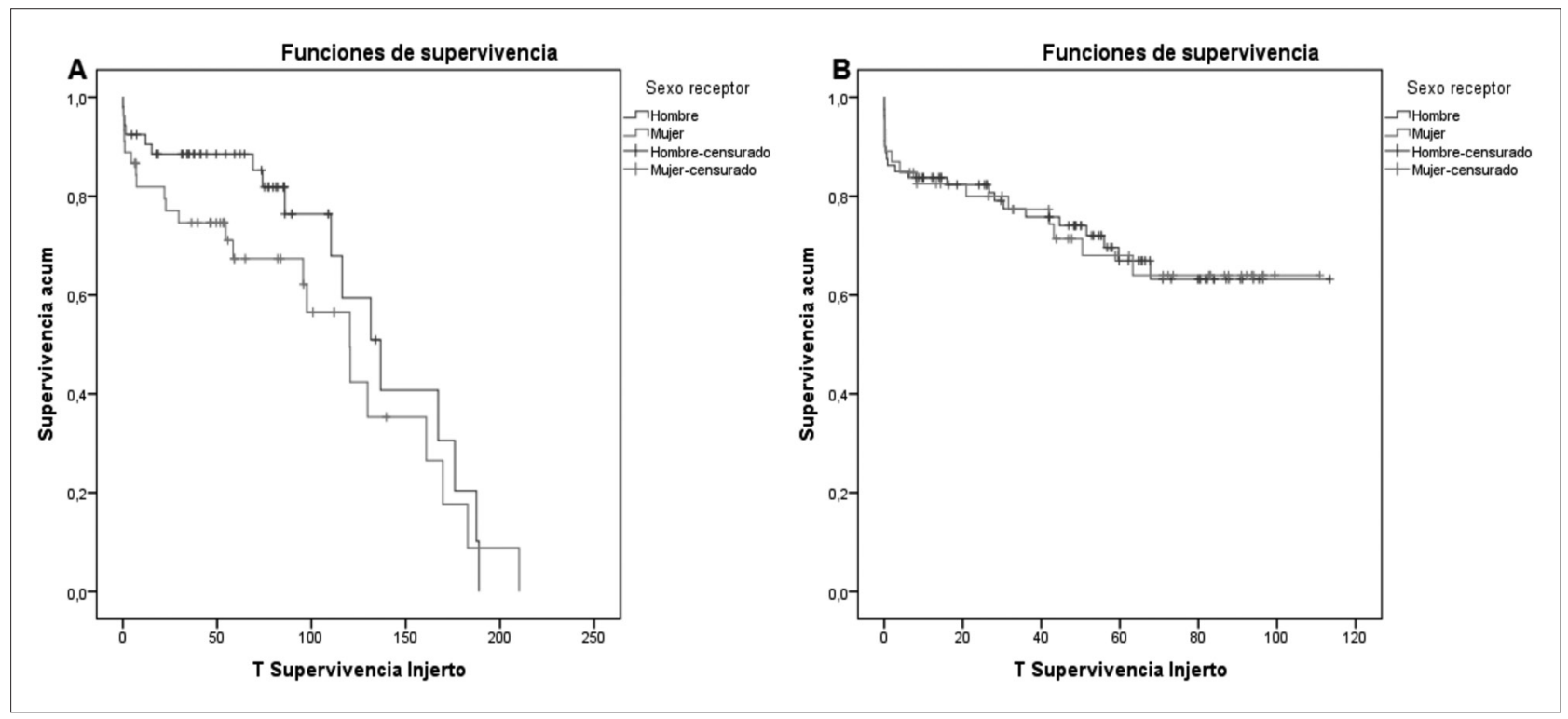

Figura 3. - (A) Curvas de supervivencia del injerto renal de acuerdo al sexo del receptor 1994-2003. $n=99$ (B) Curvas de supervivencia del injerto renal de acuerdo sexo del receptor en el periodo 2004-2012. $n=126$.

en el período $B$ fueron cardiovasculares, infecciosas y otras causas.

Las causas de pérdida del injerto en el período $A$, fueron: nefropatía crónica del injerto $(24,1 \%)$, infecciones $(10,1 \%)$ y fracaso quirúrgico $(9,1 \%)$, y en período B fueron, complicaciones quirúrgicas ( $12 \%)$, nefropatía crónica del injerto $(8,3 \%)$ e infecciosas $(6,8 \%)$.

\section{Discusión y conclusiones}

En relación a la supervivencia del paciente los resultados obtenidos están dentro de los rangos que establece la Sociedad Nacional de Trasplante Chilena', similares a los reportados por Ticona y otros autores ${ }^{10,11}$.

En relación a la supervivencia del injerto pudimos observar, que nuestros resultados, son preocupantes ya que esta disminuyó considerablemente en el período $B$ que es más reciente y se ubica por debajo de los estándares nacionales e internacionales mínimos aceptados, así mismo otros autores como Dorado y cols. ${ }^{4}$ TiconaGarron ${ }^{10}$, Hernández y Gonzales ${ }^{11}$, Perfau y cols ${ }^{12}$, informan de mejores resultados. Contariamente Borroto y cols ${ }^{13}$ presentan unos resultados de supervivencia del injerto al año y a los 5 años inferiores a los obtenidos en nuestro estudio y mencionan que un gran número de complicaciones que producen disfunción del injerto se presentan en los primeros 30 días de evolución del mis- mo y constituyen procesos negativos que comprometen la supervivencia posterior del trasplante.

De los resultados obtenidos se aprecia que la edad del donante, influye en la supervivencia del injerto, lo que coincide con lo reportado por la literatura nacional e internacional. Se pudo observar que en ambos período el donante vivo presentó mejor supervivencia que el donante cadáver, similar a lo reportado por Ticona-Garron ${ }^{10}$, Hernández y Gonzales ${ }^{11}$ y Perfau y cols $^{12}$, destacamos que las cifras de donantes vivos en nuestra población son muy bajas y van disminuyendo (siete donantes vivos en el primer período y cuatro en el segundo) lo que nos lleva a ser cautelosos en el tratamiento de la información. Sin embargo, podemos reportar que la supervivencia del injerto en donante vivo, en el segundo período fue mayor a lo reportado por otros autores, 4,12,14 y menor a lo reportado por Hernández y Gonzales ${ }^{11}$.

Un hallazgo interesante es que el injerto de donante femenino en el período A tuvo mayor supervivencia que el injerto de donante masculino, con diferencia estadistica significativa.

La edad del receptor influyó en la supervivencia del injerto, lo que concuerda con lo informado por la literatura nacional e internacional ${ }^{4}$. En nuestro estudio los receptores mayores de 60 años fueron muy escasos pues en el periodo A fueron 1 de 98 y 5 de 126 en el 
periodo B por lo que no corresponde realizar pruebas estadísticas para comparar supervivencia con categorías de menor edad.

Se pudo observar que según el sexo del receptor la supervivencia del injerto fue similar en ambos período y para ambos sexos, lo opuesto a lo reportado por Borroto ${ }^{13}$, sin embargo cabe destacar que en el segundo período el número de receptores de sexo masculino prácticamente duplicó a las receptoras femeninas, (80/46) similar a lo reportado por Dorado ${ }^{4}$.

El tiempo de isquemia fría menor a 24 horas mantiene una mayor y más estable supervivencia, en comparación con otros estudios que reportan mejor supervivencia con tiempos menores de 20 horas como indica Palacios ${ }^{15}$ y tiempos menores de 18 horas según Pabón y cols $2005^{16}$. Concordamos con Yu LX ${ }^{17}$ quien realizó biopsias del injerto pretrasplante, constatando que tiempos de isquemia fría mayores a 24 hrs, producen mayor necrosis tubular aguda y menor supervivencia.

Las principales causas de muerte, en el primer período fueron, cardiovasculares, infecciosas y cáncer, tal como se reporta en diferentes estudios publica$\operatorname{dos}^{8,11,18}$ y en el segundo período, causas infecciosas, (sepsis, hepatitis) otras y cardiovascular, similar a lo reportado por Torres ${ }^{3}$.

Las principales causas de pérdida del injerto en el primer período, fueron: nefropatía crónica del injerto, infecciones y fracaso quirúrgico similar a lo reportado por Gallegos ${ }^{18}$ y en el segundo período fueron, complicaciones quirúrgicas, nefropatía crónica del injerto, infecciosas, coincidente a lo reportado por Torres ${ }^{3}$, Seron $^{6}$ y Hernández ${ }^{11}$.

Conclusiónes: La supervivencia del paciente es estable en el tiempo, mientras que la del injerto fue menor en comparación a estándares nacionales e internacionales. La supervivencia del injerto, fue mayor, a menor edad y con tiempos de isquemia menor a 24 horas, sin diferencias en relación al sexo del donante, receptor, y tipo de tratamiento inmunosupresor. Las infecciones fueron la primera causa de muerte y las complicaciones quirúrgicas de la pérdida del injerto.

Recibido: 10 octubre 2014

Revisado: 20 octubre 2014

Modificado: 27 octubre 2014

Aceptado: 30 octubre 2014

\section{Bibliografía}

1. Flores JC. Enfermedad renal crónica: epidemiología y factores de riesgo. Revista Médica Clínica Las Condes. 2010; 21(4): 502-507.

2. DEIS (Indicadores básicos de salud, preparada por el departamento de estadística e información de salud Minsal 2009 (páginas 5 / 93), disponible el 12/6/ 2012 en: http://www.minsal.gob.cl/portal/url/ item/94b4cblb29bc26a2e04001011e013430.pdf

3. Torres J., Torres J. Espinosa E. Gutierrez J. Sobrevida del injerto en pacientes con trasplante renal en un centro hospitalario. Gac. Med. Bol. 2011; 34 (2): 87-90.

4. Dorado A. Álvarez E. Pérez M. Renedo F. Gonzalez R. Galindo et al. Características de los pacientes registrados con enfermedad renal crónica en Castilla y León y análisis de supervivencia de los trasplantados y de sus injertos. Nefrologia 2011;31(5):57986.

5. López A. Kulisevsky J. Caballero E. El donante de órganos y tejidos: evaluación y manejo. Springer. Barcelona, 1997.

6. Serón y Moreso Disfunción crónica tardia del trasplante renal.disponible el/24/3/2014 en:http://nefrologiadigital.revistanefrologia.com

7. Andreu L. Force E. 500 cuestiones que plantea el cuidado del enfermo renal. Barcelona, Masson, 2005.

8. Sociedad Española de Nefrología. Evaluación del donante cadáver, preservación renal y donante a corazón parado. disponible el 6/4/2012 en: http:// nefrologiadigital.revistanefrologia.com.

9. Guías Clínicas Sociedad Chilena de Trasplante disponible el $5 / 11 / 2013$ en: http:// trasplante@sociedaddetrasplante.cl.

10. Ticona $A B$, Álvarez LE, Jiménez A. et al. Supervivencia del paciente e injerto renal al año de trasplante de donante fallecido; comparación con resultados de donante vivo. Rev.Mex.Urol,2010;70(6):347359.Urol.2010;70(6):347-353.

11. Hernández Marrero D, Gonzales Molina Alcaide M. Resultados globales del Tx renal. En: Lorenzo- Sellares V, López-Gómez JM. Editors. Nefrología al día(internet) 2 ed. Barcelona. Sociedad Española de Nefrología/Plusmedica; disponible el 
04/12/2012 en:http://dx.dai.org/10.3265/nefrología.2010.publ.ed80.chapyer2840

12. Pefaur J, Elgueta S, Pinto V, Aguil, Orriols M, Morales $\mathrm{J}$, et al. Sobrevida de Injertos Renales en 1000 Trasplantes Renales efectuados en el Hospital Barros Luco Trudeau, XXIII Congreso Conjunto Nefrología, Hipertensión y Trasplante (Valdivia 2006) Libro de abstracts, pág. 63.

13. Borroto G. Sinay G, Guerrero C. Infante A., González $M$. Factores de riesgo e impacto en la supervivencia, de las principales causas clínicas de disfunción del injerto en el primer mes del trasplante renal. Rev. Cubana Med. 2007; 46(2).

14. Crespo M. Esforzado N. Ricart M. Oppenheimer F. Resultados a largo plazo del trasplante renal de donante vivo: supervivencia de injerto y receptor Arch. Esp. Urol. 2005;58 (6):237-542.

14. Merlo C., Candusso P, Sgrosso J, Vázquez M. Variables del donante cadavérico como predictoras de la función del injerto renal al año y dos años de seguimiento. XX Congreso Latinoamericano y del Caribe de Trasplante y II Congreso Chileno de Trasplante. Viña del Mar, Chile 2009.
15. Palacios JM. Rodríguez MS: González R. Jiménez 0 . Turu I. Plubins L. et al. Influencia de histocompatibilidad HLA en sobrevida del injerto renal: análisis de 135 casos. Rev. Chilena de Cirugía, 2003. 54 (3): 231-234.

16. Pabón M. Rojas J. Manzi E. Badiel M. Mesa L. Castillo G. Predicción de sobrevida del injerto a corto y largo plazo mediante el uso de índices gamagráficos en receptores de trasplante renal. Acta Médica Colombiana, vol. 30,(2):45-49.

17. Yul X, Zeng LH, Fu SJ, Miao Y. Quality renal graft function is predictor and risk factor or rejection. Di Yi Jun Yi Da Xue Bao. 2005; 28 (7): 812-6.

18. Gallegos E, Pérez J. Llamas F, El aumento de la supervivencia de los trasplantes renales: un reto para la nefrología del siglo XX 2006,2(2).Disponible el 3 de 9 2013: http://www.researchgate.net/publication/28110573.

19. Hernández D, Moreso, F. ¿Ha mejorado la superviviencia del injerto tras el trasplante renal en la era de la moderna inmunosupresión?. Nefrología, 33 (1):14-26. 